\title{
Metal-free glycosylation with glycosyl fluorides in liquid $\mathrm{SO}_{\mathbf{2}}$
}

\author{
Krista Gulbe ${ }^{1}$, Jevgeṇija Lugiṇina ${ }^{1}$, Edijs Jansons ${ }^{1}$, Artis Kinens ${ }^{2,3}$ and Māris Turks ${ }^{* 1}$
}

Open Access

\author{
Full Research Paper \\ Address: \\ ${ }^{1}$ Institute of Technology of Organic Chemistry, Faculty of Materials \\ Science and Applied Chemistry, Riga Technical University, P. \\ Valdena str. 3, Riga, LV-1048, Latvia, ${ }^{2}$ Latvian Institute of Organic \\ Synthesis, Aizkraukles str. 21, Riga, LV-1006, Latvia and \\ ${ }^{3}$ Department of Chemistry, University of Latvia, Jelgavas str. 1, Riga, \\ LV-1004, Latvia \\ Email: \\ Māris Turks* - maris.turks@rtu.Iv \\ * Corresponding author \\ Keywords: \\ fluorosulfite; glycosyl fluoride; Lewis acid; liquid sulfur dioxide; \\ metal-free glycosylation
}

\author{
Beilstein J. Org. Chem. 2021, 17, 964-976. \\ https://doi.org/10.3762/bjoc.17.78 \\ Received: 06 February 2021 \\ Accepted: 17 April 2021 \\ Published: 29 April 2021 \\ Associate Editor: J. A. Murphy \\ (c) 2021 Gulbe et al.; licensee Beilstein-Institut. \\ License and terms: see end of document.
}

\begin{abstract}
Liquid $\mathrm{SO}_{2}$ is a polar solvent that dissolves both covalent and ionic compounds. Sulfur dioxide possesses also Lewis acid properties, including the ability to covalently bind Lewis basic fluoride ions in a relatively stable fluorosulfite anion $\left(\mathrm{FSO}_{2}^{-}\right)$. $\mathrm{Herein} \mathrm{we}^{-}$ report the application of liquid $\mathrm{SO}_{2}$ as a promoting solvent for glycosylation with glycosyl fluorides without any external additive. By using various temperature regimes, the method is applied for both armed and disarmed glucose and mannose-derived glycosyl fluorides in moderate to excellent yields. A series of pivaloyl-protected $O$ - and $S$-mannosides, as well as one example of a $C$-mannoside, are synthesized to demonstrate the scope of the glycosyl acceptors. The formation of the fluorosulfite species during the glycosylation with glycosyl fluorides in liquid $\mathrm{SO}_{2}$ is proved by ${ }^{19} \mathrm{~F}$ NMR spectroscopy. A sulfur dioxide-assisted glycosylation mechanism that proceeds via solvent separated ion pairs is proposed, whereas the observed $\alpha, \beta$-selectivity is substrate-controlled and depends on the thermodynamic equilibrium.
\end{abstract}

\section{Introduction}

The glycosylation reaction is still one of the most important and basic synthetic strategies in carbohydrate chemistry that provides access to the various types of glycoconjugates [1-4]. Due to the large diversity of glycosyl donors and acceptors there is no general glycosylation method developed so far. To ensure high yielding, as well as regio- and stereoselective glycosidic bond formation, a proper combination of glycosyl donor and acceptor, protecting and leaving groups, promoter, solvent and temperature has to be applied.

In 1981, Mukaiyama et al. introduced glycosyl fluorides [5] as a new class of glycosyl donors [6]. The $\mathrm{C}-\mathrm{F}$ bond is one of the strongest single bonds in the realm of organic compounds with a bond dissociation energy (BDE) of $570 \mathrm{~kJ} / \mathrm{mol}$ [7]. Thus, 
glycosyl fluorides possess a considerably higher thermal and chemical stability compared to the corresponding chlorides (BDE $432 \mathrm{~kJ} / \mathrm{mol}$ ) and bromides (BDE $366 \mathrm{~kJ} / \mathrm{mol}$ ). Due to the advantageous stability during purification, handling and storage, glycosyl fluorides have become widely used glycosyl donors in glycoconjugate synthesis $[8,9]$. Furthermore, varied reactivity between differentially protected glycosyl fluorides as well as between glycosyl fluorides and other glycosyl donors makes these substrates relevant for more effective glycosylation via orthogonal activation $[10,11]$. According to the hard-soft acid-base (HSAB) theory the fluoride leaving group is considered to be a hard Lewis base $[12,13]$. Consequently, a series of fluoride-activating systems containing hard Lewis acidic centers have been published following the first report [7,14-17]. Among these promoters $\mathrm{Sn}(\mathrm{II})$ species $\left(\mathrm{SnCl}_{2}-\mathrm{AgX}, \mathrm{X}=\mathrm{ClO}_{4}\right.$ or $\left.\mathrm{B}\left(\mathrm{C}_{6} \mathrm{~F}_{5}\right)_{4}\right)[6,18]$, group IVB metallocenes $\left(\mathrm{Cp}_{2} \mathrm{MCl}_{2}-\mathrm{AgClO}_{4}\right.$, $\mathrm{M}=\mathrm{Zr}, \mathrm{Hf}, \mathrm{Ti}$ ) [19-21], $\mathrm{BF}_{3} \cdot \mathrm{OEt}_{2}$ [22] and protic acids ( $\mathrm{TfOH}$ $\left.\mathrm{HClO}_{4}, \mathrm{HB}\left(\mathrm{C}_{6} \mathrm{~F}_{5}\right)_{4}\right)$ [23] are the most frequently used. During the last decade, apart from reports on novel promoters $\left(\mathrm{Hf}(\mathrm{OTf})_{4} \text { [24], } \mathrm{InI}_{3} \text { [25], In(OTf }\right)_{3}$ [26], $\mathrm{B}\left(\mathrm{C}_{6} \mathrm{~F}_{5}\right)_{3}$ [27]) and coupling partners [28], great attention has been paid to a stereoselective glycosylation by sterically fixed glycosyl fluorides as glycosyl donors [29-31]. The enhanced stability of glycosyl fluorides has also allowed to develop a straightforward protecting-group-free strategy towards oligosaccharides and glycopeptides under basic aqueous conditions [32,33]. Nevertheless, most of the conventional conditions for glycosyl fluoride activation have considerable drawbacks in terms of atom efficiency and environmental impact. These methods generally require (1) stoichiometric amounts of promoters, often heavy metals; (2) multiple additives (co-promoter, molecular sieves, acid scavenger) to facilitate the reaction and/or suppress formation of side-products; (3) low temperatures; (4) complex experimental procedures. Additionally, the majority of the methods reported to date have been applied only for the synthesis of $O$ [4,34,35] and $C$-glycosides [36] and by employing more reactive armed [1] glycosyl fluorides.

In glycosylation reactions the solvent plays a critical role in terms of stabilizing the oxocarbenium ion intermediate and/or affecting the $\alpha, \beta$-selectivity [1]. In 2017, Matheu et al. reported a "green" glycosylation procedure by employing supercritical $\mathrm{CO}_{2}\left(\mathrm{scCO}_{2}\right)$ as a weakly Lewis acidic reaction medium [37] The method was successfully applied for the synthesis of $O$-glycosides from disarmed glycosyl chlorides and bromides in the absence of additional promoter. Herein we disclose a related concept by applying liquid $\mathrm{SO}_{2}$. In contrast to $\mathrm{scC}_{2}$, liquid $\mathrm{SO}_{2}$ is a polar Lewis acidic solvent and due to its relatively high boiling point (bp $-10{ }^{\circ} \mathrm{C}$ ) and low vapor pressure (ca. 3 bar at $20^{\circ} \mathrm{C}$ ) it can be easily liquefied and handled in its liquid state [38]. Advantages of liquid $\mathrm{SO}_{2}$ over conventional solvents are:
(1) it is aprotic solvent with Lewis acid properties; (2) it dissolves both covalent and ionic compounds [39]; (3) it has good price-quality ratio: $\leq 5 \mathrm{EUR} / \mathrm{kg}$ for the high-purity product $\left(99.98 \%, \mathrm{H}_{2} \mathrm{O}\right.$ content $\left.\leq 50 \mathrm{ppm}\right)$; (4) it can be easily recycled by changing temperature and/or pressure regimes. The latter approach is used on industrial scale, where processes dealing with a recirculation of $\mathrm{SO}_{2}$ in a closed contour are well known. Since the first report by Walden at the beginning of the 20th century [40], a variety of Lewis acid-mediated chemical transformations [41-45], especially those with carbenium ion intermediates [46-56], have benefited from the use of liquid $\mathrm{SO}_{2}$ as the reaction medium. To the best of our knowledge, there has been only one example where liquid $\mathrm{SO}_{2}$ has been applied as the glycosylation medium to stabilize the oxocarbenium ion formed from glycosyl perchlorate that is generated in situ from glycosyl chloride and $\mathrm{AgClO}_{4}$ [56]. Apart from that, $\mathrm{SO}_{2}$ has considerable affinity to the Lewis basic halide ions [5759]. Kuhn et al. [60] and later Eisfield and Regitz [61] have published ab initio studies on the stability of halosulfites $\mathrm{HalSO}_{2}{ }^{-}(\mathrm{Hal}=\mathrm{F}, \mathrm{Cl}, \mathrm{Br}$ or I $)$ that can be formed between halide ions and the $\mathrm{SO}_{2}$ molecule. They disclosed that the formation of fluorosulfite anion $\left(\mathrm{FSO}_{2}{ }^{-}\right)$has the highest energy gain and it appears to be stable even in highly polar solvents $(\varepsilon \leq 45)$, while all other halosulfites may dissociate. Thus, we proposed that a plausible formation of the fluorosulfite species and stabilization of the oxocarbenium ion intermediate could facilitate the glycosylation with glycosyl fluorides as glycosyl donors in liquid $\mathrm{SO}_{2}$ without the need of external promoter.

\section{Results and Discussion}

We started our study by short screening of the glycosylation conditions in liquid $\mathrm{SO}_{2}$ (Table 1). To avoid a potential cleavage of acid-labile protecting groups and to obtain an easily analyzable reaction mixture, pivaloyl-protected mannosyl fluoride $\boldsymbol{\alpha} \mathbf{- 1 a}$ as a relatively stable disarmed glycosyl donor was selected as a model substrate. Reactions were carried out in a pressure reactor equipped with a glass tube. By employing a slight excess of 2-phenylethanol (2a) as a glycosyl acceptor, the reaction temperature was optimized to $100{ }^{\circ} \mathrm{C}$ (Table 1 , entry 2 ). At this temperature full conversion of mannosyl fluoride $\alpha$-1a was achieved and the desired $O$-mannoside 3a was isolated in a high yield and $\alpha$-selectivity. Hemiacetal $\alpha-4$ was isolated as the only side-product formed via glycosyl donor hydrolysis with the water present in commercial $\mathrm{SO}_{2}$ [62]. To note, at lower temperatures (Table 1, entry 1 ) no reaction was observed and mannosyl fluoride $\alpha-\mathbf{1 a}$ was fully recovered. Recently, Pedersen et al. have studied the vessel effect on the $\mathrm{C}-\mathrm{F}$ bond activation of glucosyl fluorides [63]. They have proposed an autocatalytic glycosylation by $\mathrm{SiF}_{4}$ generated in situ form initially released HF that reacts with silicates of the glassware surface. To clarify the role of a glass vessel in our case, several 
Table 1: Screening of conditions for glycosylation in liquid $\mathrm{SO}_{2}{ }^{\text {a }}$

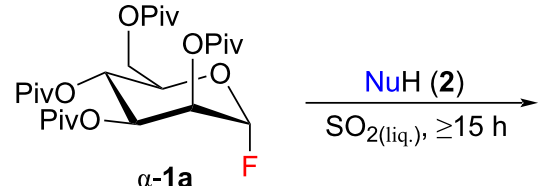

$\alpha-1 \mathbf{a}$

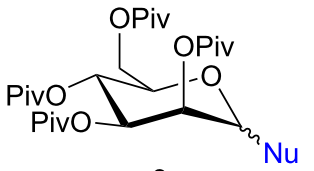

3

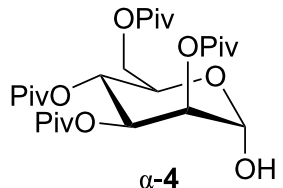

\begin{tabular}{|c|c|c|c|c|c|c|c|}
\hline entry & $\mathrm{NuH}$ & (equiv) & $T\left({ }^{\circ} \mathrm{C}\right)$ & additive (equiv) & $\alpha / \beta$ ratio $^{b}$ & yield $3(\%)^{c}$ & yield $\alpha-4(\%)^{c}$ \\
\hline 1 & \multirow{5}{*}{$2 a$} & 1.1 & 30 to 80 & - & \multicolumn{3}{|c|}{ NR } \\
\hline 2 & & 1.1 & 100 & - & $97: 3$ & $3 a, 87$ & 12 \\
\hline $3^{\mathrm{d}, \mathrm{e}}$ & & 1.1 & 100 & - & $94: 6$ & $3 a, 8$ & 40 \\
\hline $4^{d, f}$ & & 3.0 & 100 & - & $96: 4$ & $3 a, 23$ & 35 \\
\hline $5^{d}$ & & 3.0 & 150 & - & $97: 3$ & $3 a, 69$ & 30 \\
\hline 6 & & 1.0 & 100 & - & $\alpha$-only & $3 b, 67$ & 27 \\
\hline 7 & & 1.7 & 100 & $4 \AA \mathrm{MS}$ & $\alpha$-only & $3 b, 34$ & 15 \\
\hline 8 & & 1.1 & 100 & HMDSO (1.1) & \multicolumn{3}{|c|}{ NR } \\
\hline 9 & $2 b$ & 1.7 & 100 & allyl-TMS (2.2) & \multicolumn{3}{|c|}{ NR } \\
\hline
\end{tabular}

aUnless otherwise stated, reactions were carried out by using $0.193-0.771 \mathrm{mmol}$ of $\alpha-1 \mathrm{a}$ and $25 \pm 5 \mathrm{~g}$ of liquid $\mathrm{SO}_{2}$ in a pressure reactor containing a glass tube. betermined by ${ }^{1} \mathrm{H}$ NMR analysis of the crude reaction mixture. ${ }^{c}$ Yield of isolated product. ${ }^{\mathrm{d}}$ Reaction carried out in a pressure reactor containing a PTFE tube. ${ }^{5} 53 \%$ of $\alpha-1$ a was recovered. ${ }^{\dagger} 48 \%$ of $\alpha-1$ a was recovered. $\mathrm{NR}=$ no reaction; $\mathrm{MS}=$ molecular sieves; $\mathrm{HMDSO}=\mathrm{hexamethyl-}$ disiloxane; TMS = trimethylsilyl.

experiments were carried out in a pressure reactor equipped with a PTFE tube (Table 1, entries 3-5). Under previously optimized reaction conditions $\left(100{ }^{\circ} \mathrm{C}\right.$, Table 1 , entry 2$)$, mannoside 3a was isolated in only $8 \%$ yield (Table 1 , entry 3 ). The yield was increased to $23 \%$ when acceptor $\mathbf{2 a}$ was added in an excess (3.0 equiv, Table 1, entry 4). Finally, full conversion of fluoride $\alpha-\mathbf{1 a}$ and sufficient yield of desired product $\mathbf{3 a}$ were reached with 3.0 equiv of nucleophile at $150{ }^{\circ} \mathrm{C}$ (Table 1 , entry $5)$. Thus, in contrast to the previous report [63], in our case the reaction was not fully stopped by changing the reaction vessel from glass to PTFE tube. At this point, we can confirm the ability of $\mathrm{SO}_{2}$ to activate the glycosyl fluoride with a probable co-promoting assistance of a glass vessel. Next, in order to increase the yield of mannoside $\mathbf{3 b}$ formed from a less reactive secondary alcohol $\mathbf{2} \mathbf{b}$, various additives were tested (Table 1, entries 7-9). Presence of basic molecular sieves (4 $\AA$ ) as a drying agent led to lower yield and did not suppress the formation of hemiacetal $\alpha-\mathbf{4}$ (Table 1, entry 7), while no reaction was observed when additives containing a fluorophilic silicon center were used (Table 1, entries 8 and 9). The inhibitory effect of basic molecular sieves may point to the presence and contributory role of protic acid ( $\mathrm{HF}$ or $\left.\mathrm{H}_{2} \mathrm{SO}_{3}\right)$ in the course of the reaction [64]. Whereas, silyl additives can react with alcohol yielding silyl ether $[65,66]$ that do not react further with glycosyl fluoride $\alpha$-1a under our conditions. The formation of silyl ether was detected in a crude reaction mixture by NMR spectroscopy.
When the optimized model reaction (Table 1, entry 2 ) between mannosyl fluoride $\alpha-\mathbf{1 a}$ and 2-phenylethanol (2a) was carried out in pure conventional solvents $(\mathrm{MeCN}, \mathrm{THF}$, toluene or DCM) often used for glycosylation, no reaction was observed (Table 2, entries 1, 4, 6 and 9). Only traces of mannoside 3a and/or hemiacetal $\alpha-\mathbf{4}$ were detected by NMR spectroscopy in the presence of $\mathrm{H}_{3} \mathrm{PO}_{4}$ as a protic acid additive having a similar $\mathrm{p} K_{\mathrm{a}}$ value to that of $\mathrm{H}_{2} \mathrm{SO}_{3}$ that is likely to be present in liquid $\mathrm{SO}_{2}$ (Table 2, entries 3 and 8) [55]. Thus, the previously considered probable contributory effect of $\mathrm{H}_{2} \mathrm{SO}_{3}$ can be ruled out. Further, in combination with polar aprotic Lewis basic solvents (MeCN, THF) [67] sulfur dioxide was deactivated (Table 2, entries 2 and 5), while in less polar solvents (toluene, DCM) the presence of sulfur dioxide was clearly advantageous and glycoside 3a was isolated in good yields (Table 2, entries 7 and 10).

Next, the reactivity of various mannosyl halides $\alpha-\mathbf{1 a}-\mathbf{c}$ towards $O$ - and $S$-nucleophiles were compared under optimized reaction conditions (Table 3). In the case of 2-phenylethanol (2a) as an $O$-nucleophile, a similar reactivity, yield of mannoside $\mathbf{3 a}$ and $\alpha$-selectivity were observed (Table 3 , entries $1-3$ ) among all the halides $\alpha-\mathbf{1 a}-\mathbf{c}$, although mannosyl chloride $\boldsymbol{\alpha}-\mathbf{1 b}$ and bromide $\alpha-1 c$ were not fully consumed. The superior reactivity of glycosyl fluoride $\alpha-\mathbf{1 a}$ in liquid $\mathrm{SO}_{2}$ compared to other halides was clearly demonstrated when thiol $\mathbf{2 c}$ was used as an acceptor (Table 3, entries 4-6). S-Mannoside 3c was isolated from 
Table 2: Comparison with conventional solvents. ${ }^{a}$

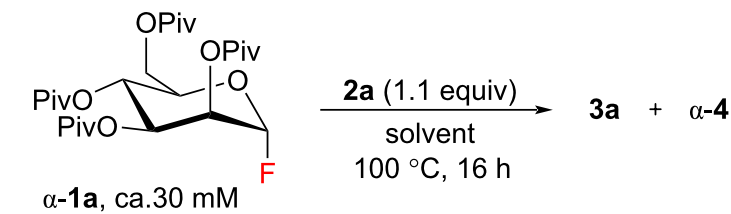

\begin{tabular}{|c|c|c|}
\hline entry & solvent & $\begin{array}{l}\text { yield }(\%)^{b} \\
\left(\alpha / \beta \text { ratio }^{c}\right)\end{array}$ \\
\hline 0 & liquid $\mathrm{SO}_{2}$ & 3a, $87(97: 3)$ \\
\hline 1 & $\mathrm{MeCN}$ & NR \\
\hline $2^{d}$ & $\mathrm{MeCN}+\mathrm{SO}_{2}$ & NR \\
\hline 3 & $\mathrm{MeCN}+$ conc. $\mathrm{H}_{3} \mathrm{PO}_{4}{ }^{\mathrm{e}}$ & traces of $3 a \& \alpha-4$ \\
\hline 4 & THF & NR \\
\hline $5^{d}$ & $\mathrm{THF}+\mathrm{SO}_{2}$ & NR \\
\hline 6 & toluene & NR \\
\hline $7^{d}$ & toluene $+\mathrm{SO}_{2}$ & 3a, 62\% ( $\alpha$-only) \\
\hline 8 & toluene + conc. $\mathrm{H}_{3} \mathrm{PO}_{4}{ }^{f}$ & traces of $\alpha-4$ \\
\hline 9 & DCM & NR \\
\hline $10^{d}$ & $\mathrm{DCM}+\mathrm{SO}_{2}$ & $\begin{array}{c}3 a, 65 \%(98: 2) \\
\alpha-4,32 \%\end{array}$ \\
\hline
\end{tabular}

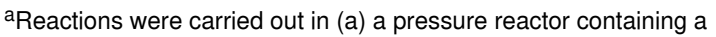
glass tube for entries 2, 5, 7, 9, and 10; (b) a glass pressure tube for

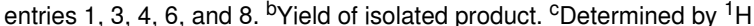
NMR analysis of a crude reaction mixture. dSolutions were prepared by bubbling $\mathrm{SO}_{2}$ through the selected solvent for $10 \mathrm{~min}$. ${ }^{\mathrm{e}} 1.2$ equiv. $f_{1.4}$ equiv. mannosyl fluoride $\alpha$-1a in twice as high yield as from the corresponding chloride $\alpha-\mathbf{1 b}$ or bromide $\boldsymbol{\alpha}-\mathbf{1 c}$. The stability of the latter in liquid $\mathrm{SO}_{2}$ at such a high temperature was unexpected due to their generally established labile nature. Additionally, when competitive glycosylation reactions in the presence of both $O$ - and $S$-nucleophiles were performed, all mannosyl halides $\alpha$-1a-c gave $O$-mannoside $\mathbf{3 a}$ as the major product in 58 to $71 \%$ yield, while overall yield of products 3a,c varied from $77 \%$ for $\alpha-\mathbf{1 b}$ to quant. for $\alpha-\mathbf{1 a}$ (Table S1, Supporting Information File 1).

Pivaloyl-protected mannosyl fluoride $\alpha-\mathbf{1 a}$ was further applied for the synthesis of various $O-, S$ - and $C$-glycosides to demonstrate the scope of acceptors compatible with our glycosylation conditions (Scheme 1). Most of the primary alcohols (2a, 2d-3f) were glycosylated in high yields (up to $91 \%$ ). In the case of less reactive secondary alcohols $(\mathbf{2 b}, \mathbf{2 h}, \mathbf{2} \mathbf{j}, \mathbf{2 k})$ and phenol (2l) better yields were obtained when 3.0 equiv of nucleophile were used. For example, the yield of mannoside $\mathbf{3 1}$ was increased from $34 \%$ to $79 \%$ when the amount of phenol (2l) was changed from 1.0 to 3.0 equiv. Similar reactivity relationships were observed in a series of thiols (2c, $\mathbf{2 m}-\mathbf{p})$, but the glycosylation yields comparing to the corresponding alcohols were slightly higher (up to 95\%). By employing 2-phenylethanethiol (2c), a gram-scale synthesis of mannoside $\mathbf{3 c}$ was successfully demonstrated. Diminished reactivity towards glycosylation of some alcohols $(\mathbf{2 g}, \mathbf{2 i}, \mathbf{2 r})$ in liquid $\mathrm{SO}_{2}$ can be explained by possible formation of stable carbocation species [52]. Thus, in contrast to the other primary alcohols, an excess of 3.0 equiv

Table 3: Reactivity comparison of mannosyl halides $\alpha-1 a-c$ in liquid $\mathrm{SO}_{2} \cdot{ }^{a}$
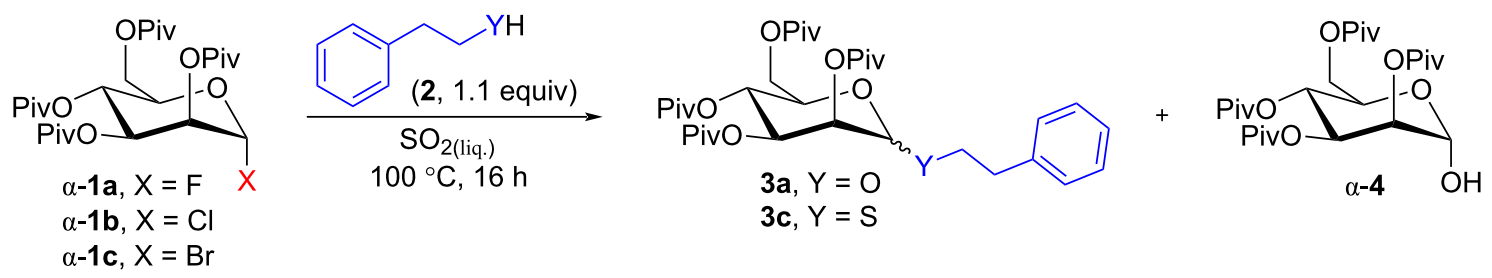

$\alpha-1 c, X=B r$

\begin{tabular}{|c|c|c|c|c|c|c|c|c|}
\hline \multirow[t]{2}{*}{ entry } & \multirow[t]{2}{*}{$\alpha-1$} & \multirow[t]{2}{*}{2} & \multicolumn{4}{|c|}{ composition of a crude reaction mixture $(\mathrm{mol} \%)^{b}$} & \multirow[t]{2}{*}{$\alpha: \beta$ ratio $^{b}$} & \multirow[t]{2}{*}{ yield $3(\%)$} \\
\hline & & & $\alpha-1$ & $\alpha-3$ & $\beta-3$ & $\alpha-4$ & & \\
\hline 1 & $\mathbf{a}$ & \multirow{3}{*}{$\begin{array}{c}\mathbf{2 a} \\
(Y=O)\end{array}$} & ND & 86 & 3 & 11 & $97: 3$ & $3 a, 87$ \\
\hline 2 & b & & 4 & 85 & 2 & 9 & $98: 2$ & $3 a, 91$ \\
\hline 3 & C & & 14 & 80 & 2 & 4 & $98: 2$ & $3 a, 81$ \\
\hline 4 & $\mathbf{a}$ & \multirow{3}{*}{$\begin{array}{c}\text { 2c } \\
\left(Y^{\prime}=S\right)\end{array}$} & ND & 82 & 18 & ND & $82: 18$ & $3 c, 95$ \\
\hline 5 & b & & 46 & 44 & 2 & 8 & $96: 4$ & $3 c, 46$ \\
\hline 6 & c & & 42 & 42 & 10 & 6 & $81: 19$ & 3c. 49 \\
\hline
\end{tabular}

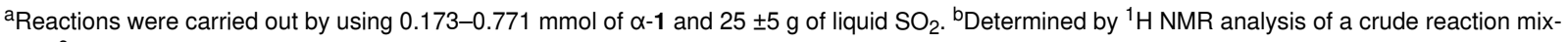
ture. ${ }^{c}$ Yield of isolated product. 

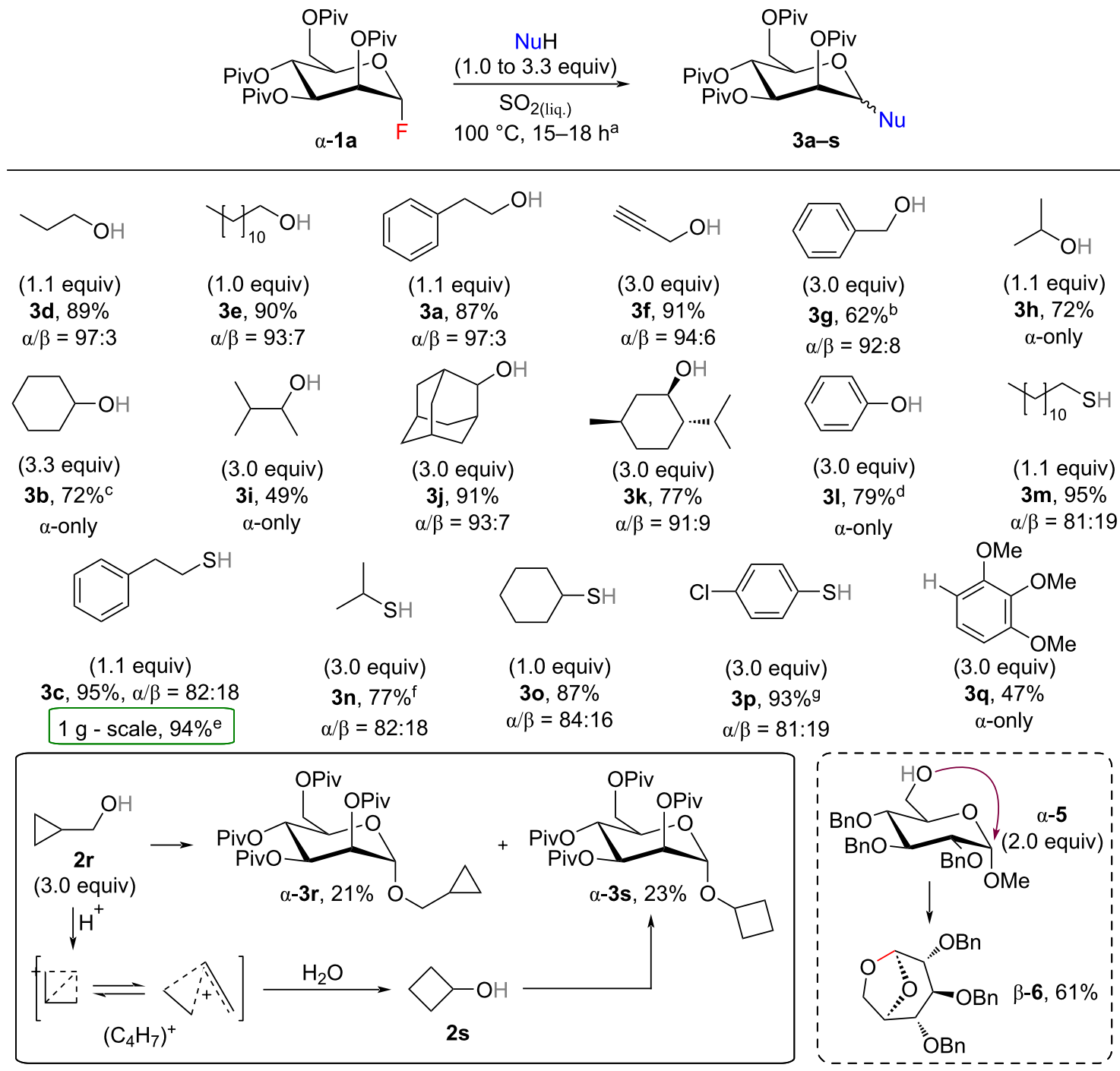

Scheme 1: Scope of glycosyl acceptors for glycosylation with pivaloyl-protected mannosyl fluoride $\alpha-1$ a in liquid $\mathrm{SO}_{2}$. ${ }^{\text {a Unless }}$ otherwise stated, reactions were carried out by using $0.193-0.771 \mathrm{mmol}$ of $\alpha-1 \mathrm{a}$ and $25 \pm 5 \mathrm{~g}$ of liquid $\mathrm{SO}_{2} ; \alpha / \beta$ ratios were determined by ${ }^{1} \mathrm{H}$ NMR analysis of the crude reaction mixture. ${ }^{b} 56 \%$ yield when 1.1 equiv $\mathrm{NuH}$ was used. ${ }^{c} 67 \%$ yield when 1.0 equiv $\mathrm{NuH}$ was used. $\mathrm{d}_{34 \%}$ yield when 1.0 equiv $\mathrm{NuH}$ was used. eReaction conditions: 1.2 equiv $\mathrm{NuH}, 43 \mathrm{~g}$ liquid $\mathrm{SO}_{2} ; \alpha / \beta=83: 17 .{ }^{\dagger} 42 \%$ yield when 1.1 equiv $\mathrm{NuH}$ was used. $959 \%$ yield when 1.0 equiv $\mathrm{NuH}$ was used.

was required to provide a moderate $62 \%$ yield of mannoside $\mathbf{3 g}$ when benzyl alcohol (2g) was used as an acceptor. Next, the formation of tertiary carbenium ion from 3-methyl-butan-2-ol (2i) via 1,2-hydrogen shift in an initial formed secondary carbocation [52] explains the relatively low yield of mannoside $\mathbf{3 i}$. The same problem was observed when 1-adamantanol (S5) was used as a glycosyl acceptor and the desired mannoside was formed in only 6\% NMR yield (Figure S1, Supporting Information File 1). Finally, a mixture of mannosides $\alpha-3 \mathbf{r}$ and $\alpha-3$ s was obtained when cyclopropylmethanol (2r) was applied. The cyclopropylmethyl carbocation $\left(\mathrm{C}_{4} \mathrm{H}_{7}^{+}\right)$, which is generated in liquid $\mathrm{SO}_{2}$ medium, can undergo a rearrangement to form a cyclobutyl carbocation [68]. The latter can be trapped by a water molecule forming cyclobutanol (2s) that further reacts with the glycosyl donor. Additionally, our glycosylation approach in liquid $\mathrm{SO}_{2}$ was applied for the synthesis of $C$-glycoside 3q by employing electron-rich 1,2,3-trimethoxybenzene (2q). Also binucleophiles $\mathbf{7 a}$ and $\mathbf{7 b}$ were glycosylated with a slight excess of mannosyl fluoride $\alpha$-1a to form bis-mannosides $\alpha-\mathbf{8}$ in good yields (Scheme 2). In a series of pivaloyl-protected mannosides 3 a substrate-controlled $\alpha$-selectivity due to the favoring effect of both neighboring ester-type protecting groups and the anomeric effect was observed [3].

On the other hand, mixing of glycosyl donor $\alpha-1 a$ and 1-Omethyl glucoside $\alpha-5$ under the developed glycosylation condi- 


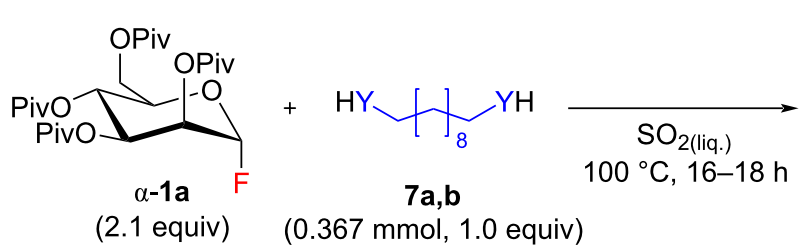

(2.1 equiv)

( 0.367 mmol, 1.0 equiv)

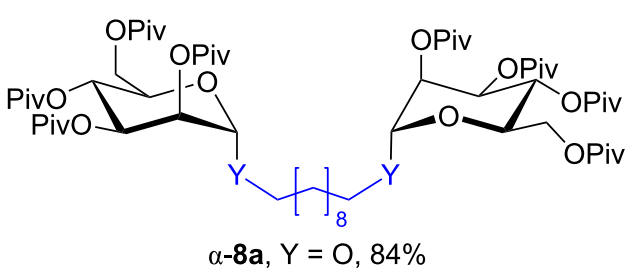

$\alpha-8 \mathbf{a}, Y=0,84 \%$

$\alpha-8 b, Y=S, 76 \%$

Scheme 2: Glycosylation of binucleophiles $\mathbf{7 a , b}$ in liquid $\mathrm{SO}_{2}$.

tions did not provide the expected disaccharide (Scheme 1). Instead, the formation of 1,6-anhydroglucose $\beta-6$ via intramolecular attack $[69,70]$ was detected, while fluoride $\alpha$-1a stayed unchanged. By employing fully protected 1-O-methyl glucoside $\alpha$-S9 as a glycosyl donor, we have demonstrated that methoxide can act as a mediocre leaving group in liquid $\mathrm{SO}_{2}$ (Scheme S1, Supporting Information File 1). Other limitations for the glycosylation with mannosyl fluoride $\alpha$-1a include steric hindrance and the presence of a Lewis basic nitrogen or fluorophilic trimethylsilyl group in the molecule of the glycosyl acceptor (Figure S1, Supporting Information File 1).

To our delight, no cleavage of the pivaloyl protecting groups in liquid $\mathrm{SO}_{2}$ medium was observed and the main side-product formed in the series of mannosides $\mathbf{3}$ was the previously mentioned tetra- $O$-pivaloyl mannopyranose $\alpha-4$. In some experiments traces of 1,1'-mannoside $\alpha, \alpha-\mathbf{S 1 4}$ formed in the reaction between hemiacetal $\alpha \mathbf{- 4}$ and glycosyl donor $\alpha-\mathbf{1 a}$ were detected (see Supporting Information File 1) [71].

Further, we turned our attention to the reactivity of other glycosyl fluorides in liquid $\mathrm{SO}_{2}$. We continued with pivaloylprotected glucosyl fluoride $\beta-9$ (Scheme 3). The reaction conditions were optimized to $100{ }^{\circ} \mathrm{C}$ and 3.0 equiv of nucleophile (Table S3, Supporting Information File 1). The target glucosides 10 were obtained in a moderate yield and $\beta$-selectivity induced through the neighboring ester type protecting group assistance. At lower temperatures the glycosylation yield was lower, although full conversion of glucosyl fluoride $\beta-\mathbf{9}$ was still ob- served. Compared to the analogue mannose derivative $\alpha-\mathbf{1 a}$, glucose $\beta-9$ turned out to be less stable and more prone to various side-reactions. A series of side-products formed by hydrolysis and protecting group migrations were detected and their structures are proposed (see Supporting Information File 1).

Next, glycosyl fluorides $\boldsymbol{\alpha - 1 1}$ and $\boldsymbol{\alpha - \mathbf { 1 2 }}$ containing more acidsensitive acetyl protecting groups were applied for the glycosylation of 2-phenylethanol (2a) and 2-phenylethanethiol (2c) in liquid $\mathrm{SO}_{2}$ (Table 4). A temperature screening was performed to identify optimal reaction conditions (Table S4, Supporting Information File 1). The acetyl-protected mannosyl fluoride $\alpha \mathbf{- 1 1}$ gave the desired mannosides $\mathbf{1 3}$ in a moderate yield and $\alpha$-selectivity. The latter was comparable to the selectivity observed for the pivaloyl-protected mannosides 3 . This time a couple of mono-deprotected side-products was observed (see Supporting Information File 1). The reactivity of acetyl-protected glucosyl fluoride $\boldsymbol{\alpha - 1 2}$ was similar to that of mannose $\alpha$-11. Glucosides 14 were isolated in a moderate yield, but without any $\alpha, \beta$-selectivity due to the mismatched interaction between the anomeric effect and neighboring protecting group assistance. The diminished selectivity compared to the series of pivaloyl-protected glucosides $\mathbf{1 0}$ leads to the conclusion that the Lewis basic carbonyl oxygen of the acetyl group is more coordinated and less nucleophilic in liquid $\mathrm{SO}_{2}$ than the carbonyl oxygen of the pivaloyl group. The profile of side-products in this glucose series was similar to that observed for fluoride $\beta-9$ (see Supporting Information File 1).
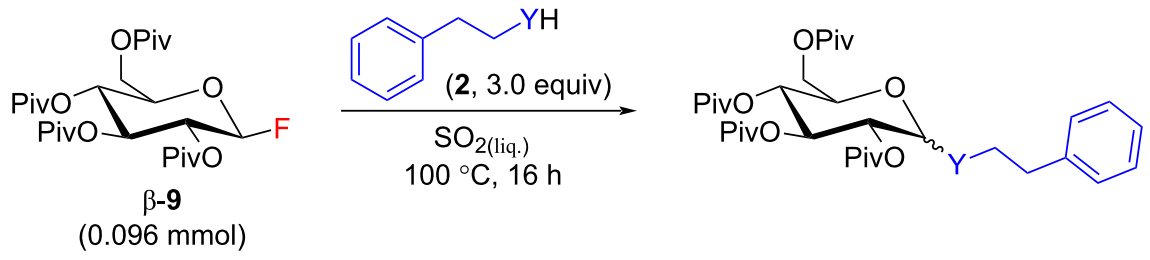

10a, $Y=0,61 \%(\alpha / \beta=15: 85)$

10b, $Y=S, 57 \%(\alpha / \beta=24: 76)$ 
Table 4: Acetyl protected manno- and glucopyranosyl fluorides $\alpha-11$ and $\alpha-12$ as glycosyl donors in liquid $\mathrm{SO}_{2}{ }^{a}$

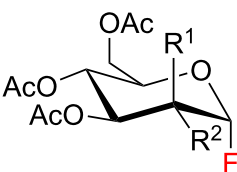

$\alpha-11, R^{1}=O A c, R^{2}=H$

$\alpha-12, R^{1}=H, R^{2}=O A C$

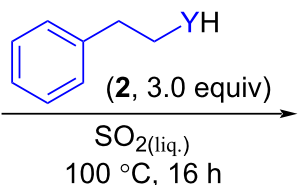

$100{ }^{\circ} \mathrm{C}, 16 \mathrm{~h}$

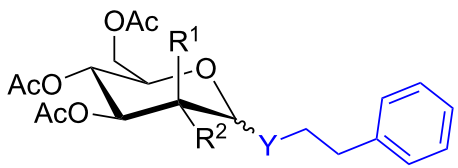

13, $R^{1}=O A c, R^{2}=H$

14, $R^{1}=H, R^{2}=O A C$

\begin{tabular}{|c|c|c|c|c|}
\hline entry & glycosyl fluoride & $Y(2)$ & $\alpha / \beta$ ratio $b$ & yield $(\%)^{\mathrm{C}}$ \\
\hline 1 & \multirow{2}{*}{$\alpha-11$} & 0 & $91: 9$ & $13 a, 55$ \\
\hline 2 & & $S$ & $78: 22$ & 13b, 67 \\
\hline 3 & \multirow{2}{*}{$\alpha-12$} & $\mathrm{O}$ & $54: 46$ & $14 a, 43$ \\
\hline 4 & & $S$ & $48: 52$ & 14b, 76 \\
\hline
\end{tabular}

aReactions were carried out in a scale of $0.277-0.300 \mathrm{mmol}(\alpha-11$ or $\alpha-12) .{ }^{b}$ Determined by ${ }^{1} \mathrm{H}$ NMR analysis of a crude reaction mixture. ${ }^{\mathrm{c} Y i e l d}$ of isolated product.

The armed benzyl-protected glycosyl fluorides $\alpha-\mathbf{1 5}$ and $\mathbf{1 6}$ were more reactive than their acylated analogues and the corresponding glycosides $\mathbf{1 7}$ and $\mathbf{1 8}$ were obtained at lower tempera- tures (Scheme 4). The reaction temperature for mannosyl fluoride $\alpha-\mathbf{1 5}$ was optimized to $30{ }^{\circ} \mathrm{C}$ (Table S5, Supporting Information File 1). At higher temperature desired mannoside 17a

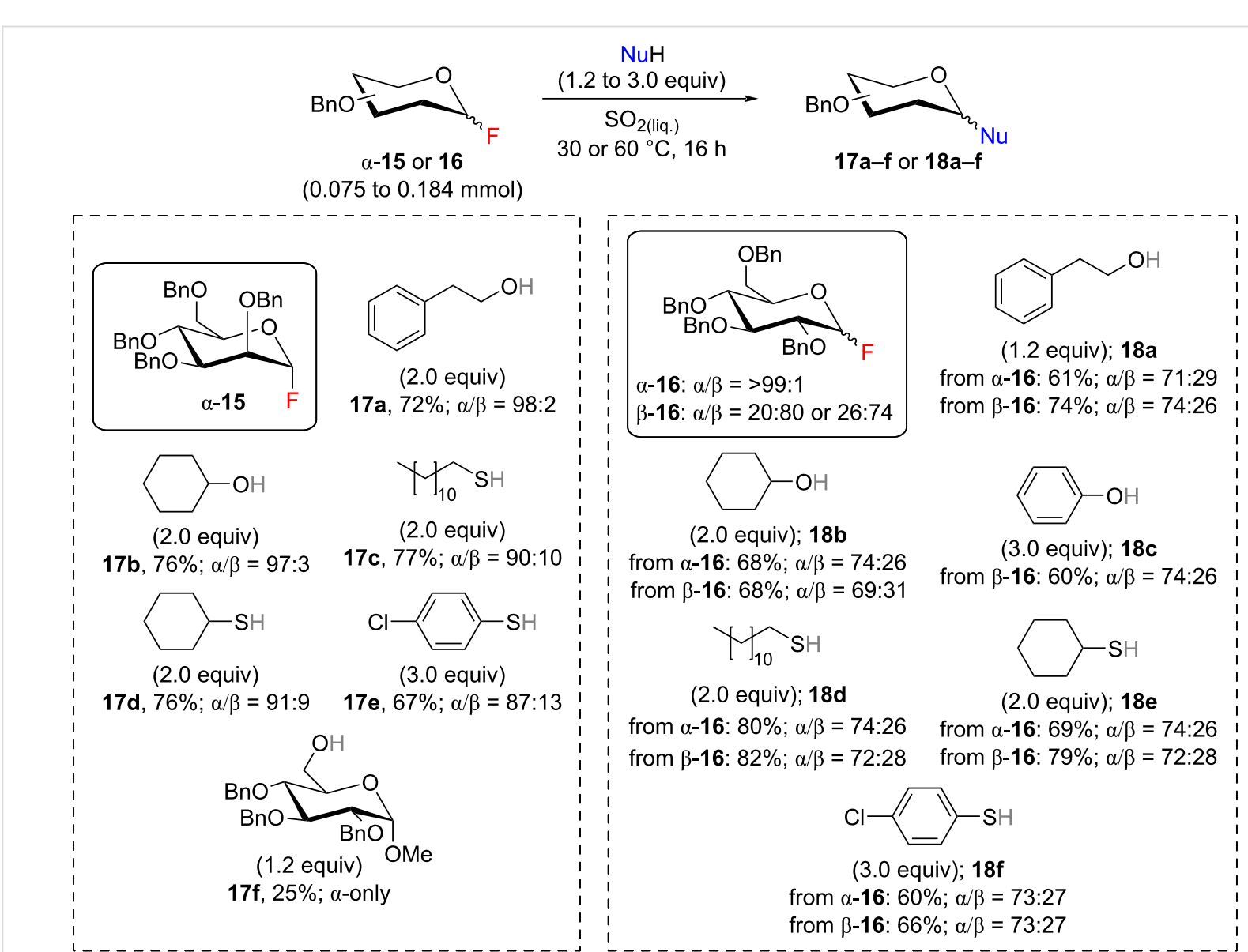

Scheme 4: Benzyl protected manno- and glucopyranosyl fluorides $\alpha-15$ and 16 as glycosyl donors in liquid $\mathrm{SO}_{2}$. Reactions were carried out at $30{ }^{\circ} \mathrm{C}$ for mannosyl fluoride $\alpha-15$ and glucosyl fluoride $\alpha-16$; at $60^{\circ} \mathrm{C}$ for glucosyl fluoride $\beta-16$. Anomeric ratios were determined by HPLC analysis. 
was not observed, whereas at $-10^{\circ} \mathrm{C}$ its yield was decreased. Under optimal conditions mannosides $\mathbf{1 7 a}$-e were obtained in good yields and $\alpha$-selectivity. Importantly, due to increased reactivity of glycosyl donor $\alpha \mathbf{- 1 5}$ at lower temperature, we have also managed to obtain disaccharide 17f, albeit in low yield. Interestingly, a different temperature regime was adopted for benzyl-protected glucosyl fluoride 16 depending on its anomeric ratio (Table S6, Supporting Information File 1). Thus, the glycosylation temperature for the glucosyl fluoride containing an excess of $\beta$-anomer $\beta$-16 was optimized to $60{ }^{\circ} \mathrm{C}$, while for the more reactive $\alpha$-anomer $\alpha-16$ it was decreased to $30{ }^{\circ} \mathrm{C}$. Regardless of the anomeric ratio, the desired $O$ - and $S$-glucosides 18a-f were isolated in good yields. Besides, glycosylation of primary nucleophiles with benzyl-protected glucosyl fluoride gave better yields (18a and 18d) than with the corresponding acylated analogues $\beta-\mathbf{9}$ and $\alpha \mathbf{- 1 1}$ described above. It was also found that the glycosylation stereoselectivity with glucosyl fluoride $\mathbf{1 6}$ did not depend on the anomeric ratio of glucosyl fluoride 16: both anomers of $\mathbf{1 6}$ yielded glucosides 18 in similar anomeric ratios with excess of the $\alpha$-anomer. As expected, in the absence of an ester type protecting group at $\mathrm{C} 2$ position, for both series of benzyl protected glycosides $\alpha$-selectivity was observed solely due to the anomeric effect.

The Lewis acidic medium of liquid $\mathrm{SO}_{2}$ was also facilitating for the synthesis of 2-deoxy glucoside $\mathbf{2 0}$ from corresponding fluoride $\alpha-19$ in $91 \%$ yield and $\operatorname{good} \alpha$-selectivity at $-10{ }^{\circ} \mathrm{C}$ (Scheme 5). Due to the absence of a neighboring group at $\mathrm{C} 2$ position, the stereoselective synthesis of 2-deoxy glycosides is challenging [72-74]. We hypothesize that the stabilization of the oxocarbenium ion intermediate in a form of a dioxolenium ion by the remote protecting group in $\mathrm{C} 3$ or $\mathrm{C} 6$ position could be the reason for such a good $\alpha$-selectivity in liquid $\mathrm{SO}_{2}$ [75].

Within this study, several experiments were also carried out to test the reactivity of peracylated manno- and glucopyranoses in liquid $\mathrm{SO}_{2}$ (Table S7, Supporting Information File 1). Most of these glycosyl donors were not fully consumed at $100{ }^{\circ} \mathrm{C}$ and formed a complex mixture of monosaccharides.
Finally, in order to make our glycosylation procedure more attractive and more accessible to the synthetic community we have demonstrated an application of saturated solutions of $\mathrm{SO}_{2}$ in conventional solvents that do not require a specific equipment, but can be performed in widely available glass pressure tubes (Table 5). In this context it has technically a similarity with ammonia solutions in organic solvents. We prepared saturated $\mathrm{SO}_{2}$ solutions in toluene and DCM. The concentration of $\mathrm{SO}_{2}$ in saturated solutions was determined by iodometric titration. As shown in Table 5, higher yields were obtained in DCM solutions. The yield of $O$-mannoside $\mathbf{3 a}$ was even higher when the glycosylation between mannosyl fluoride $\alpha$-1a and 2-phenylethanol (2a) was performed in a gram-scale by applying a solvent/substrate ratio of 10:1 (mL/g) (Table 5, entries 2 and 5). A diminished yield was observed for $S$-mannoside $3 \mathbf{c}$ when the glycosylation was carried out in saturated DCM solution (64\%) instead of pure $\mathrm{SO}_{2}(95 \%)$ (Table 5, entry 6). No difference was observed between the yields of thioglucoside 18d in liquid $\mathrm{SO}_{2}$ or its solution in DCM (Table 5, entry 7).

By employing benzyl-protected glucosyl fluoride 16 with different anomeric ratios, we have demonstrated that the stereochemical outcome of the glycosylation in liquid $\mathrm{SO}_{2}$ does not depend on the configuration of the anomeric center of the glycosyl donor. This observation points to the formation of a solvent-separated ion pair (SSIP) between the oxocarbenium ion and a counteranion, for example, fluorosulfite. At the same time, according to the Lewis base properties characterized by lithium cation basicity ( $\mathrm{LiCB}$ ) liquid $\mathrm{SO}_{2}(76.3)$ is similar to DCM (83) [67]. Thus, liquid $\mathrm{SO}_{2}$ could be classified as a noncoordinating solvent that unlikely coordinates to the oxocarbenium ion intermediate and affects the glycosylation stereoselectivity [1]. As a result, we can conclude that the stereoselectivity of the glycosylation in liquid $\mathrm{SO}_{2}$ is substrate-controlled and approaches a thermodynamic equilibrium determined by the anomeric effect or interference of both the anomeric effect and the assistance of the neighboring ester-type protecting group.

Next, we have also observed that the anomerization of the glycosylated products towards their thermodynamic equilib-

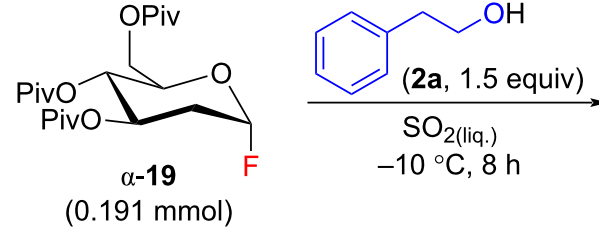

$(0.191 \mathrm{mmol})$

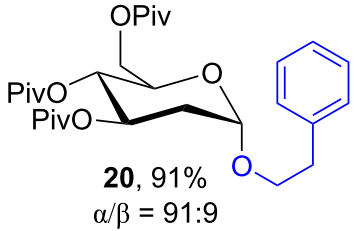

$\alpha / \beta=91: 9$

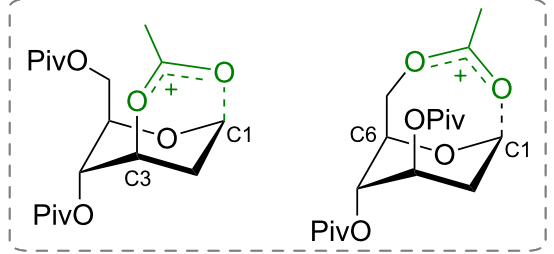

dioxolenium ion 
Table 5: Glycosylation with mannosyl fluoride $\alpha-1 \mathrm{a}$ and glucosyl fluoride $\alpha-16$ in saturated $\mathrm{SO}_{2}$ solutions. ${ }^{a}$

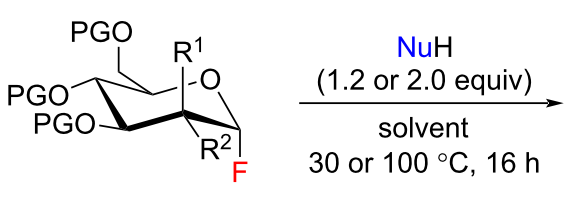

$\alpha-1 \mathbf{a}\left(R^{1}=\right.$ OPG $=$ OPiv, $\left.R^{2}=H\right)$

$\alpha-16\left(R^{1}=H, R^{2}=O P G=O B n\right)$

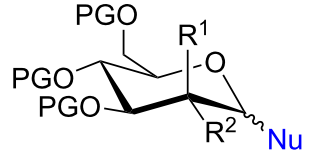

from $\alpha-1 a: 3 a \& 3 c$

from $\alpha-16: 18 d$

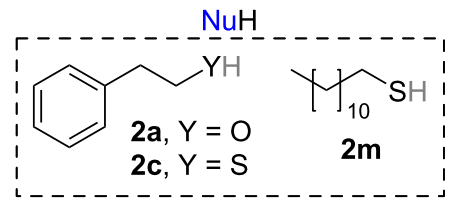

$2 a, Y=0$

2c, $Y=S$

$2 \mathrm{~m}$

\begin{tabular}{cccccccc}
\hline entry & glycosyl fluoride & scale $(\mathrm{g})$ & solvent & conc. $(\mathrm{mL} / \mathrm{g})$ & $\mathrm{NuH}$ & $\alpha / \beta$ ratio & $y^{\mathrm{b}}$ \\
\hline 1 & $\alpha-1 \mathbf{a}$ & 0.2 & & 75 & $\mathbf{2 a}$ & $>99: 1$ & $\mathbf{3 a}, 66$ \\
2 & & 1.5 & $\begin{array}{c}2.7 \mathrm{M} \mathrm{SO}_{2} \\
\text { in toluene }\end{array}$ & 10 & $\mathbf{2 a}$ & $95: 5$ & $\mathbf{3 a}, 75$ \\
3 & & 0.1 & & 75 & $\mathbf{2 c}$ & $90: 10$ & $\mathbf{3 c}, 32$ \\
\hline 4 & $\alpha-1 \mathbf{a}$ & 0.2 & & 75 & $\mathbf{2 a}$ & $98: 2$ & $\mathbf{3 a}, 84$ \\
5 & & 1.5 & $2.0 \mathrm{M} \mathrm{SO}_{2}$ & 10 & $\mathbf{2 a}$ & $96: 4$ & $\mathbf{3 a}, 94$ \\
6 & & 0.1 & in DCM & 75 & $\mathbf{2 c}$ & $86: 14$ & $\mathbf{3 c}, 64$ \\
7 & $\alpha-16$ & 0.1 & & 20 & $\mathbf{2 m}$ & $64: 36$ & $\mathbf{1 8 d}, 84$ \\
\hline
\end{tabular}

aReactions were carried out in glass pressure tubes; reaction conditions: (entries 1-6) 1.2 equiv $\mathrm{NuH}$, at $100{ }^{\circ} \mathrm{C}$; (entry 7$) 2.0$ equiv $\mathrm{NuH}$, at $30{ }^{\circ} \mathrm{C}$. ${ }^{b}$ Determined by ${ }^{1} \mathrm{H}$ NMR (entries 1-6) or HPLC (entry 7) analysis of a crude reaction mixture. ${ }^{c}$ Yield of isolated product.

rium is promoted by the species formed during the glycosylation reaction [76]. Thus, when anomerically pure thiomannoside $\beta$-3c was subjected to the glycosylation conditions $\left(100{ }^{\circ} \mathrm{C}\right.$, $16 \mathrm{~h}$ ) in liquid $\mathrm{SO}_{2}$ without any additives, no anomerization was observed and the tested substrate $\beta-\mathbf{3 c}$ was almost fully recovered. In contrast, when the same thiomannoside $\beta-\mathbf{3 c}$ was added to the glycosylation mixture containing 1-dodecanethiol (2m) and mannosyl fluoride $\alpha$-1a or bromide $\alpha$-1c (Table 6), anomer- ization occurred approaching the anomeric ratio observed initially for mannoside $3 \mathbf{c}(\alpha / \beta=82: 18$, Scheme 1$)$.

Finally, we proved the formation of the fluorosulfite species by employing ${ }^{19} \mathrm{~F}$ NMR spectroscopy (Figure 1). Glycosylation of the reaction mixture was treated with $\mathrm{Et}_{3} \mathrm{~N}$ to stabilize the possibly formed fluorosulfite anions in form of an ammonium salt. The ${ }^{19} \mathrm{~F}$ NMR spectra of the water-soluble components

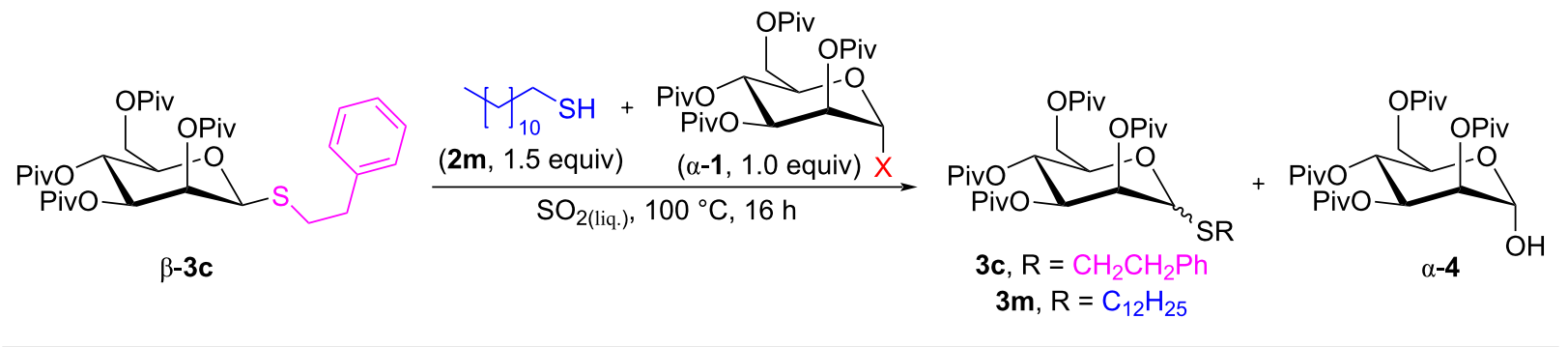

\begin{tabular}{|c|c|c|c|c|c|c|c|}
\hline \multirow[t]{2}{*}{ entry } & \multirow[t]{2}{*}{$\alpha-1$} & \multicolumn{4}{|c|}{ composition of a crude reaction mixture $(\mathrm{mol} \%)^{a}$} & \multicolumn{2}{|c|}{$\alpha / \beta$ ratio $^{a}$} \\
\hline & & $3 c$ & $3 m$ & $\alpha-1$ & $\alpha-4$ & $3 c$ & $3 \mathrm{~m}$ \\
\hline 1 & $\left(X^{\mathbf{a}}=\mathrm{F}\right)$ & 48 & 35 & ND & 17 & $71: 29$ & $82: 18$ \\
\hline 2 & $(\mathrm{X}=\mathrm{Br})$ & 39 & 48 & 13 & ND & $81: 19$ & $82: 18$ \\
\hline
\end{tabular}

aDetermined by ${ }^{1} \mathrm{H}$ NMR analysis of a crude reaction mixture. 
was than compared to the standard obtained from the reaction between TBAF and $\mathrm{SO}_{2}$. The peak that corresponds to the $\mathrm{FSO}_{2}{ }^{-}$anion was observed at $38.34 \mathrm{ppm}$ (TFA as an external standard, $-76.55 \mathrm{ppm})$ [77].
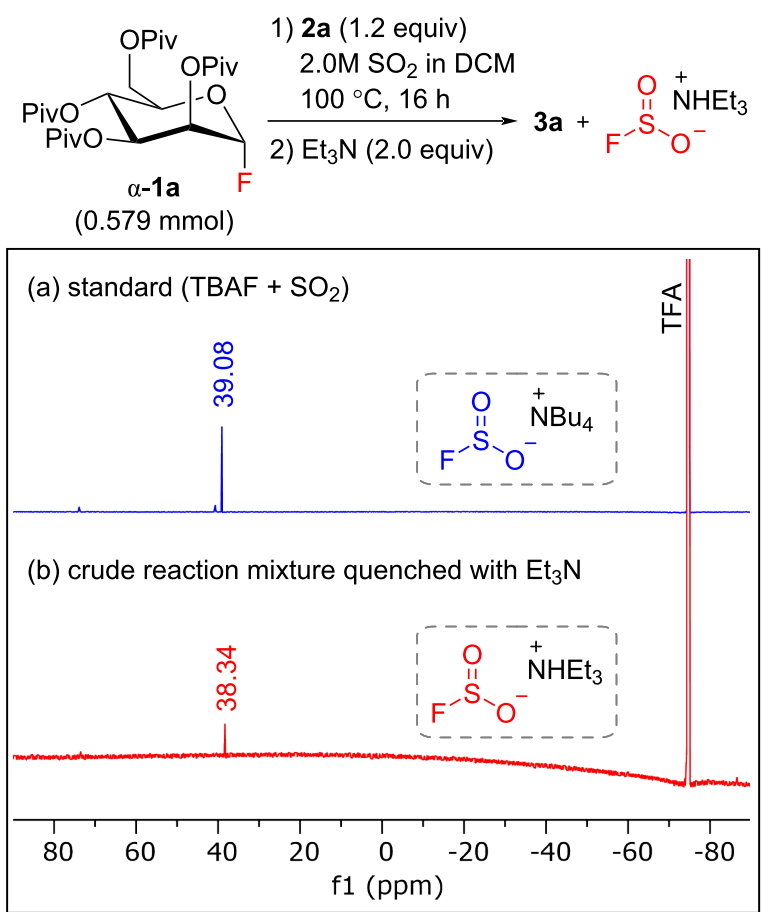

Figure 1: Detection of the $\mathrm{FSO}_{2}{ }^{-}$species by ${ }^{19} \mathrm{~F} \mathrm{NMR}(471 \mathrm{MHz}$, $\mathrm{D}_{2} \mathrm{O}$ ).

Also DFT calculations were performed on the model reaction $\alpha-\mathbf{1 1}+\mathrm{MeOH} \rightarrow \alpha-\mathbf{1 3 c}$ to elucidate the influence of $\mathrm{SO}_{2}$ on the dissociation of the glycosidic C-F bond [78] (Figure 2). Indeed, it was found that the coordination of the Lewis acidic $\mathrm{SO}_{2}$ to the fluoride (transition state TS- $\mathrm{A}^{\neq}$versus TS-A $\left(\mathrm{SO}_{2}\right)^{\ddagger}$ ) decreases the $\mathrm{C}-\mathrm{F}$ bond dissociation energy $(\Delta \Delta \mathrm{G})$ by $10.6 \mathrm{kcal} / \mathrm{mol}$. The formation of the neighboring group stabilized the oxocarbenium ion (dioxolenium ion) and its reaction with alcohol leads to the experimentally observed glycosides and the $\mathrm{FSO}_{2} \mathrm{H}$ adduct. We assume that due to the formation of the latter also substrates, which do not possess the participating group at $\mathrm{C} 2$ position, still react through the oxocarbenium ion intermediate.

\section{Conclusion}

In summary, novel sulfur dioxide-assisted and metal-free glycosylation conditions by employing a combination of glycosyl fluoride as the glycosyl donor and liquid $\mathrm{SO}_{2}$ as both solvent and promoter have been developed. Due to the absence of any external additive, the presented method is considered to be an atom efficient and environmentally friendly synthetic approach. The glycosylation conditions in liquid $\mathrm{SO}_{2}$ have been optimized for both disarmed and armed mannose- and glucosederived glycosyl fluorides, and novel conditions have been successfully applied for the synthesis of $O-, S$ - and $C$-glycosides in moderate to excellent yields. The glycosylation in liquid $\mathrm{SO}_{2}$ is proposed to proceed via a solvent-separated ion pair and with stereoselectivity that is substrate-controlled and presents a thermodynamic equilibrium. The latter was clearly demonstrated when the more challenging 2-deoxyglucosyl fluoride was used as a glycosyl donor and the assistance of a remote acyl-protecting group provided good $\alpha$-selectivity. The initially proposed formation of the fluorosulfite species during the glycosylation in liquid $\mathrm{SO}_{2}$ was proved by employing ${ }^{19} \mathrm{~F} \mathrm{NMR}$ spectroscopy and DFT calculations. Finally, a more conventional experimental procedure has been provided for the application of saturated $\mathrm{SO}_{2}$ solution in DCM or toluene. This

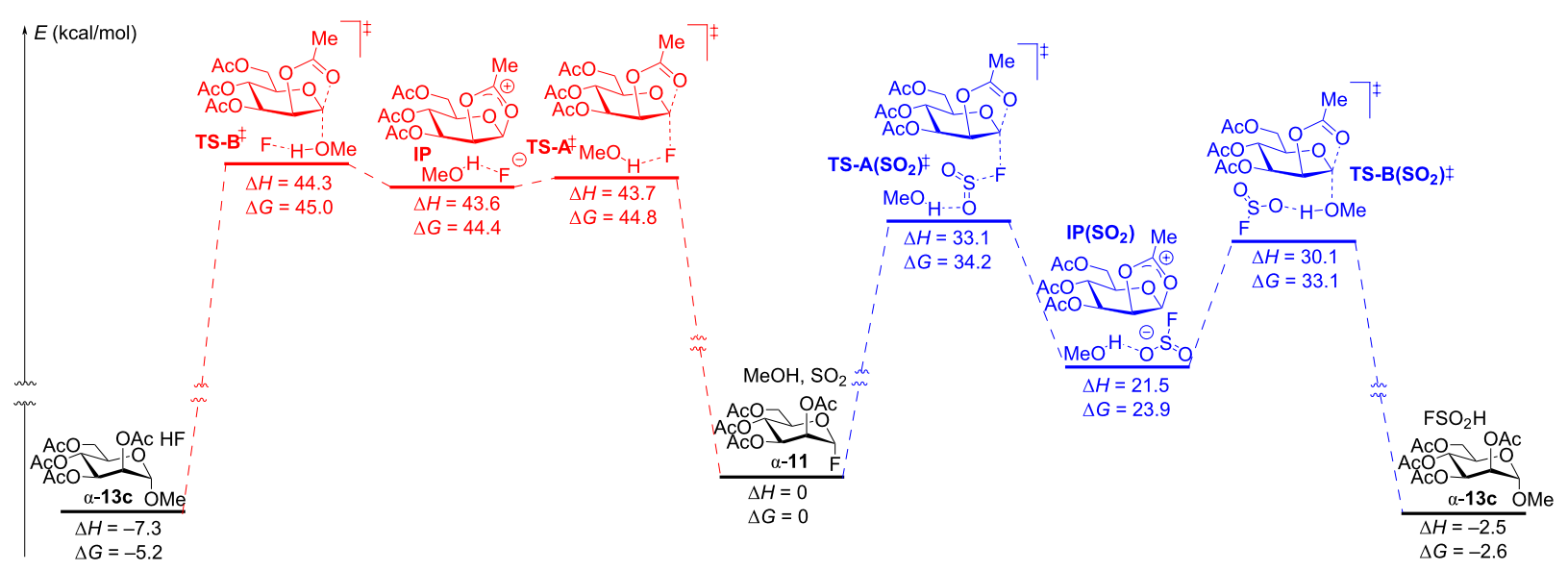

Figure 2: Computational study of reaction mechanism $\alpha-\mathbf{1 1}+\mathrm{MeOH} \rightarrow \alpha-\mathbf{1 3 c}$ in the presence of and in absence of $\mathrm{SO}_{2}(\mathrm{Gaussian} 09, \mathrm{Revision}$ D.01; Gaussian, Inc.; m052x method and the $6-31+g(d)$ basis set). Enthalpy and Gibbs free energy values referenced against the starting value for the substrates and catalyst are given in $\mathrm{kcal} / \mathrm{mol}$. 
protocol does not require specific equipment and the reactions can be performed in widely available glass pressure tubes.

\section{Supporting Information}

\section{Supporting Information File 1}

Experimental procedures; experimental data for synthesized compounds; competitive glycosylation of $O$ - and $S$-nucleophiles; problematic glycosyl acceptors; reaction optimization data; reactivity of other glycosyl donors; proposed structures of side-products; detailed description of ${ }^{19}$ F NMR studies; stability tests for various glycosyl donors.

[https://www.beilstein-journals.org/bjoc/content/ supplementary/1860-5397-17-78-S1.pdf]

\section{Supporting Information File 2}

Copies of NMR spectra.

[https://www.beilstein-journals.org/bjoc/content/ supplementary/1860-5397-17-78-S2.pdf]

\section{Supporting Information File 3}

DFT calculations.

[https://www.beilstein-journals.org/bjoc/content/ supplementary/1860-5397-17-78-S3.pdf]

\section{Funding}

This work was financially supported by the Latvian Council of Science Grant No. LZP-2018/1-0315. K.G. thanks Riga Technical University doctoral student grant DOK.OKTI/20.

\section{ORCID ${ }^{\circledR}$ iDs}

Krista Gulbe - https://orcid.org/0000-0003-1301-6805 Jevgeṇija Lugiṇina - https://orcid.org/0000-0001-8147-9698 Artis Kinens - https://orcid.org/0000-0003-1992-525X Māris Turks - https://orcid.org/0000-0001-5227-0369

\section{References}

1. Bennett, C. S., Ed. Selective Glycosylations: Synthetic Methods and Catalysts; Wiley-VCH: Weinheim, Germany, 2017. doi:10.1002/9783527696239

2. Fraser-Reid, B. O.; Tatsuta, K.; Thiem, J.; Coté, G. L.; Flitsch, S.; Ito, Y.; Kondo, H.; Nishimura, S.-i.; Yu, B., Eds. Glycoscience: Chemistry and Chemical Biology; Springer: Berlin, Germany, 2008.

3. Demchenko, A. V., Ed. Handbook of Chemical Glycosylation: Advances in Stereoselectivity and Therapeutic Relevance; Wiley-VCH: Weinheim, Germany, 2008. doi:10.1002/9783527621644

4. Nielsen, M. M.; Pedersen, C. M. Chem. Rev. 2018, 118, 8285-8358. doi:10.1021/acs.chemrev.8b00144
5. Yokoyama, M. Carbohydr. Res. 2000, 327, 5-14. doi:10.1016/s0008-6215(99)00324-9

6. Mukaiyama, T.; Murai, Y.; Shoda, S.-i. Chem. Lett. 1981, 10, 431-432. doi:10.1246/cl.1981.431

7. Shoda, S.-I.; Kulkarni, S. S.; Gervay-Hague, J. Glycoside Synthesis from Anomeric Halides. In Handbook of Chemical Glycosylation: Advances in Stereoselectivity and Therapeutic Relevance; Demchenko, A. V., Ed.; Wiley-VCH: Weinheim, Germany, 2008; pp 29-93. doi:10.1002/9783527621644.ch2

8. Shimizu, M.; Togo, H.; Yokoyama, M. Synthesis 1998, 799-822. doi:10.1055/s-1998-2070

9. Williams, S. J.; Withers, S. G. Carbohydr. Res. 2000, 327, 27-46. doi:10.1016/s0008-6215(00)00041-0

10. Kaeothip, S.; Demchenko, A. V. Carbohydr. Res. 2011, 346, 1371-1388. doi:10.1016/j.carres.2011.05.004

11. Kulkarni, S. S.; Wang, C.-C.; Sabbavarapu, N. M.; Podilapu, A. R.; Liao, P.-H.; Hung, S.-C. Chem. Rev. 2018, 118, 8025-8104. doi:10.1021/acs.chemrev.8b00036

12. Pearson, R. G. J. Am. Chem. Soc. 1963, 85, 3533-3539. doi:10.1021/ja00905a001

13. Pearson, R. G.; Songstad, J. J. Am. Chem. Soc. 1967, 89, 1827-1836. doi:10.1021/ja00984a014

14. Toshima, K. Carbohydr. Res. 2000, 327, 15-26. doi:10.1016/s0008-6215(99)00325-0

15. Toshima, K. Glycosyl Halides. In Glycoscience: Chemistry and Chemical Biology; Fraser-Reid, B. O.; Tatsuta, K.; Thiem, J.; Coté, G. L.; Flitsch, S.; Ito, Y.; Kondo, H.; Nishimura, S.-i.; Yu, B., Eds.; Springer: Berlin, Germany, 2008; pp 429-449.

16. Mukaiyama, T.; Jona, H. Proc. Jpn. Acad., Ser. B 2002, 78, 73-83. doi:10.2183/pjab.78.73

17. Mukaiyama, T. Angew. Chem., Int. Ed. 2004, 43, 5590-5614. doi:10.1002/anie.200300641

18. Mukaiyama, T.; Maeshima, H.; Jona, H. Chem. Lett. 2001, 30, 388-389. doi:10.1246/cl.2001.388

19. Matsumoto, T.; Maeta, H.; Suzuki, K.; Tsuchihashi, I. G.-i. Tetrahedron Lett. 1988, 29, 3567-3570. doi:10.1016/0040-4039(88)85294-8

20. Suzuki, K.; Maeta, H.; Matsumoto, T. Tetrahedron Lett. 1989, 30 , 4853-4856. doi:10.1016/s0040-4039(01)80526-8

21. Matsumoto, T.; Katsuki, M.; Suzuki, K. Tetrahedron Lett. 1989, 30 , 833-836. doi:10.1016/s0040-4039(01)80628-6

22. Kunz, H.; Sager, W. Helv. Chim. Acta 1985, 68, 283-287. doi:10.1002/hlca.19850680134

23. Jona, H.; Mandai, H.; Chavasiri, W.; Takeuchi, K.; Mukaiyama, T. Bull. Chem. Soc. Jpn. 2002, 75, 291-309. doi:10.1246/bcsj.75.291

24. Manabe, S.; Ito, Y. J. Org. Chem. 2013, 78, 4568-4572. doi:10.1021/jo400282x

25. Ma, T.; Li, C.; Zhang, Z.-X.; Wang, Z.; Yu, L.; Xue, W. Synlett 2017, 28, 2633-2636. doi:10.1055/s-0036-1589121

26. Sim, J.; Kim, S.-H.; Hur, J.; Lim, C.; Kim, H. S.; Suh, Y.-G. Asian J. Org. Chem. 2019, 8, 107-110. doi:10.1002/ajoc.201800582

27. Sati, G. C.; Martin, J. L.; Xu, Y.; Malakar, T.; Zimmerman, P. M.; Montgomery, J. J. Am. Chem. Soc. 2020, 142, 7235-7242. doi:10.1021/jacs.0c03165

28. Zeng, J.; Vedachalam, S.; Xiang, S.; Liu, X.-W. Org. Lett. 2011, 13, 42-45. doi:10.1021/ol102473k

29. Okada, Y.; Asakura, N.; Bando, M.; Ashikaga, Y.; Yamada, H. J. Am. Chem. Soc. 2012, 134, 6940-6943. doi:10.1021/ja301480g

30. Heuckendorff, M.; Pedersen, C. M.; Bols, M. J. Org. Chem. 2013, 78, 7234-7248. doi:10.1021/jo4012464 
31. Motoyama, A.; Arai, T.; Ikeuchi, K.; Aki, K.; Wakamori, S.; Yamada, H. Synthesis 2018, 50, 282-294. doi:10.1055/s-0036-1590927

32. Pelletier, G.; Zwicker, A.; Allen, C. L.; Schepartz, A.; Miller, S. J. J. Am. Chem. Soc. 2016, 138, 3175-3182. doi:10.1021/jacs.5b13384

33. Wadzinski, T. J.; Steinauer, A.; Hie, L.; Pelletier, G.; Schepartz, A.; Miller, S. J. Nat. Chem. 2018, 10, 644-652. doi:10.1038/s41557-018-0041-8

34. Yang, Y.; Zhang, X.; Yu, B. Nat. Prod. Rep. 2015, 32, 1331-1355. doi:10.1039/c5np00033e

35. Pellissier, H. Tetrahedron 2005, 61, 2947-2993. doi:10.1016/j.tet.2005.01.070

36. Yang, Y.; Yu, B. Chem. Rev. 2017, 117, 12281-12356. doi:10.1021/acs.chemrev.7b00234

37. Cardona, A.; Boutureira, O.; Castillón, S.; Díaz, Y.; Matheu, M. I. Green Chem. 2017, 19, 2687-2694. doi:10.1039/c7gc00722a

38. Müller, H. Sulfur Dioxide. Ullmann's Encyclopedia of Industrial Chemistry; Wiley-VCH: Weinheim, Germany, 2012; Vol. 35, pp 73-118.

39. Burow, D. F. Liquid Sulfur Dioxide. In The Chemistry of Nonaqueous Solvents; Lagowski, J. J., Ed.; Academic Press: New York, NY, USA, 1970; Vol. 3, pp 137-185. doi:10.1016/b978-0-12-433803-6.50008-0

40. Walden, P. Ber. Dtsch. Chem. Ges. 1902, 35, 2018-2031. doi:10.1002/cber.190203502153

41. Ross, J.; Percy, J. H.; Brandt, R. L.; Gebhart, A. I.; Mitchell, J. E.; Yolles, S. Ind. Eng. Chem., Ind. Ed. 1942, 34, 924-926. doi:10.1021/ie50392a006

42. Tokura, N. Synthesis 1971, 639-645. doi:10.1055/s-1971-21781

43. Schmidt, D.; Leutbecher, H.; Conrad, J.; Klaiber, I.; Mika, S.; Greiner, G.; Beifuss, U. Synlett 2007, 1725-1729. doi:10.1055/s-2007-984506

44. Lugininina, J.; Uzuleṇa, J.; Posevins, D.; Turks, M. Eur. J. Org. Chem. 2016, 1760-1771. doi:10.1002/ejoc.201600141

45. Luginina, J.; Turks, M. Synlett 2017, 28, 939-943. doi:10.1055/s-0036-1588670

46. Olah, G. A.; Donovan, D. J. J. Am. Chem. Soc. 1978, 100, 5163-5169. doi:10.1021/ja00484a043

47. Feigel, M.; Kessler, H.; Leibfritz, D.; Walter, A. J. Am. Chem. Soc. 1979, 101, 1943-1950. doi:10.1021/ja00502a003

48. Mayr, H.; Gorath, G.; Bauer, B. Angew. Chem., Int. Ed. Engl. 1994, 33, 788-789. doi:10.1002/anie.199407881

49. Olah, G. A. Angew. Chem., Int. Ed. Engl. 1995, 34, 1393-1405. doi:10.1002/anie.199513931

50. Soares, B. G. Prog. Polym. Sci. 1997, 22, 1397-1430. doi:10.1016/s0079-6700(96)00025-1

51. Chénedé, A.; Fleming, I.; Salmon, R.; West, M. C. J. Organomet. Chem. 2003, 686, 84-93. doi:10.1016/s0022-328x(03)00548-5

52. Posevins, D.; Suta, K.; Turks, M. Eur. J. Org. Chem. 2016, 1414-1419. doi:10.1002/ejoc.201600013

53. Suta, K.; Turks, M. ACS Omega 2018, 3, 18065-18077. doi:10.1021/acsomega.8b01630

54. Leškovskis, K.; Lugiṇina, J.; Suta, K.; Turks, M. Key Eng. Mater. 2019, 800, 42-46. doi:10.4028/www.scientific.net/kem.800.42

55. Leškovskis, K.; Gulbe, K.; Mishnev, A.; Turks, M. Tetrahedron Lett. 2020, 61, 152528. doi:10.1016/j.tetlet.2020.152528

56. Igarashi, K.; Honma, T.; Irisawa, J. Carbohydr. Res. 1970, 15, 329-337. doi:10.1016/s0008-6215(00)80449-8

57. Milanova, E.; Benoit, R. L. Can. J. Chem. 1977, 55, 2807-2812. doi:10.1139/v77-390
58. Lee, K.-Y.; Kim, C.-S.; Kim, H.-G.; Cheong, M.-S.; Mukherjee, D. K.; Jung, K.-D. Bull. Korean Chem. Soc. 2010, 31, 1937-1940. doi:10.5012/bkcs.2010.31.7.1937

59. Kumar, A.; McGrady, G. S.; Passmore, J.; Grein, F.; Decken, A. Z. Anorg. Allg. Chem. 2012, 638, 744-753. doi:10.1002/zaac.201100476

60. Maulitz, A. H.; Boese, R.; Kuhn, N. J. Mol. Struct.: THEOCHEM 1995, 333, 227-232. doi:10.1016/0166-1280(94)03955-k

61. Eisfeld, W.; Regitz, M. J. Am. Chem. Soc. 1996, 118, 11918-11926. doi:10.1021/ja961398v

62. Christensen, H. M.; Oscarson, S.; Jensen, H. H. Carbohydr. Res. 2015, 408, 51-95. doi:10.1016/j.carres.2015.02.007

63. Nielsen, M. M.; Qiao, Y.; Wang, Y.; Pedersen, C. M. Eur. J. Org. Chem. 2020, 140-144. doi:10.1002/ejoc.201901755

64. Jona, H.; Takeuchi, K.; Mukaiyama, T. Chem. Lett. 2000, 29, 1278-1279. doi:10.1246/cl.2000.1278

65. Pinnick, H. W.; Bal, B. S.; Lajis, N. H. Tetrahedron Lett. 1978, 19 4261-4262. doi:10.1016/s0040-4039(01)95196-2

66. Morita, T.; Okamoto, Y.; Sakurai, H. Tetrahedron Lett. 1980, 21, 835-838. doi:10.1016/s0040-4039(00)71518-8

67. Laurence, C.; Gal, J.-F. Lewis Basicity and Affinity Scales: Data and Measurement; John Wiley \& Sons: Chichester, UK, 2010.

68. Olah, G. A.; Prakash, G. K. S.; Rasul, G. J. Am. Chem. Soc. 2008, 130, 9168-9172. doi:10.1021/ja802445s

69. Dere, R. T.; Zhu, X. Org. Lett. 2008, 10, 4641-4644. doi:10.1021/ol8019555

70. Bosco, M.; Rat, S.; Dupré, N.; Hasenknopf, B.; Lacôte, E.; Malacria, M.; Rémy, P.; Kovensky, J.; Thorimbert, S.; Wadouachi, A. ChemSusChem 2010, 3, 1249-1252. doi:10.1002/cssc.201000218

71. Araki, Y.; Watanabe, K.; Kuan, F.-H.; Itoh, K.; Kobayashi, N.; Ishido, Y. Carbohydr. Res. 1984, 127, C5-C9. doi:10.1016/0008-6215(84)85121-6

72. Jünnemann, J.; Lundt, I.; Thiem, J. Liebigs Ann. Chem. 1991, 759-764. doi:10.1002/jlac.1991199101130

73. Schene, H.; Waldmann, H. Synthesis 1999, 1411-1422. doi:10.1055/s-1999-3651

74. Toshima, K.; Kasumi, K.-i.; Matsumura, S. Synlett 1999, 813-815. doi:10.1055/s-1999-2742

75. Hansen, T.; Elferink, H.; van Hengst, J. M. A.; Houthuijs, K. J.; Remmerswaal, W. A.; Kromm, A.; Berdern, G.; van der Vorm, S.; Rijs, A. M.; Overkleeft, H. S.; Filippov, D. V.; Rutjes, F. P. J. T.; van der Marel, G. A.; Martens, J.; Oomens, J.; Codée, J. D. C.; Boltje, T. J. Nat. Commun. 2020, 11, No. 2664. doi:10.1038/s41467-020-16362-x

76. Lemieux, R. U.; Hendriks, K. B.; Stick, R. V.; James, K. J. Am. Chem. Soc. 1975, 97, 4056-4062. doi:10.1021/ja00847a032

77. Zhu, S.-Z.; Huang, Q.-C.; Wu, K. Inorg. Chem. 1994, 33, 4584-4585. doi:10.1021/ic00098a028

78. Gaussian 09, Revision D.01; Gaussian, Inc.: Wallingford, CT, USA, 2013. 


\section{License and Terms}

This is an Open Access article under the terms of the Creative Commons Attribution License (https://creativecommons.org/licenses/by/4.0). Please note that the reuse, redistribution and reproduction in particular requires that the author(s) and source are credited and that individual graphics may be subject to special legal provisions.

The license is subject to the Beilstein Journal of Organic Chemistry terms and conditions:

(https://www.beilstein-journals.org/bjoc/terms)

The definitive version of this article is the electronic one which can be found at:

https://doi.org/10.3762/bjoc.17.78 